\title{
Challenges Faced by Malaysian Government School Teachers to Conduct Online Lessons for the Secondary School Students during Covid-19 Pandemic
}

\author{
Gunasegaran Karuppannan', Buvaneswary Balasubramaniam², Fazal Mohamed Mohamed \\ Sultan ${ }^{3}$ \\ ${ }^{1}$ Assoc. Prof. Dr. in Faculty of Education and Social Sciences, UNISEL \\ ${ }^{2}$ Master of Education, Faculty of Education and Social Sciences, UNISEL \\ ${ }^{3}$ Assoc. Prof. Dr. in Faculty of Social Science and Humanities, UKM
}

\begin{abstract}
The COVID-19 pandemic has forced many educational institutes across the world to change dramatically. Teaching and learning have been undertaken remotely and on various digital platforms. In Malaysia, schools were closed for more than 6 months in the second quarter of 2020 and again experiencing school closure in May 2021. Education Ministry of Malaysia (MOE) strongly encouraged all government schools, especially the teachers and students, to use various online communications platforms to ensure the educational process remains uninterrupted. However, the COVID-19 pandemic has generated considerable challenges for the teaching and learning in government schools especially in secondary schools while using such emerging technologies. This research has two main goals. First, this journal will be analysing whether the online learning platforms used by secondary school teachers to conduct lessons during the COVID-19 period have presented any challenges to their student's learning. Secondly, the paper will then go on to address proposed solutions by developing a conceptual model to reduce the impact of such challenges. An exploratory qualitative approach will be carried out in this research, supported by literature review techniques. The data set for this journal was collected between May to June 2021 during the third wave of pandemics in Malaysia. The data gathered by interviewing various secondary school teachers in Selangor. A total of 10 teachers participated in this interview process. Those teachers interviewed disclosed various obstacles they faced when they began to use information technology platforms for their online lessons, especially the new technological platforms. These obstacles include (a) overloaded work and information. (b) unfamiliarity and inability to learn of the new online learning platform, and (c) personal health challenges related to stress and anxiety.
\end{abstract}

KEY WORDS: pandemic, education, challenges, online learning, Covid-19, qualitative, technology

\section{INTRODUCTION}

The education system has been disrupted due to the unavoidable situation of the Covid-19 pandemic. Globally, approximately 1.2 billion children from 186 countries are devastated dramatically by school closures. (Boon, 2020). In Malaysia, schools were closed for more than 6 months in second quarter of 2020 and again experiencing school closure in May 2021 (Hassan, 2021). Thus, all the academic institutes of Malaysia shifted their medium of studies from face-to-face, to online platforms. In this situation, it becomes necessary for teachers to adopt online lessons to preserve the flow of the studies.

Teachers face various remarkable challenges due to many reasons that can create deficiency in their lesson preparedness. Mostly, teachers and students face signal issues, the expansion of the data, handling technological platforms, getting feedback from students and ext. The main aim of this research is to identify the challenges that are faced by the teachers of Malaysian Government School in conducting online lessons for the secondary level. Malaysian Government schools are also adopting the online platforms in their primary and secondary schools but the adaptation is not easy for most teachers.

\section{OBJECTIVE}

i. To find out whether there is relationship with the technological issues and online teaching.

ii. To explore the challengers faced by teachers in Malaysia in virtual engagement.

iii. To analyse effectiveness of communication in delivering lessons digitally to the students.

iv. To find out the time management issues during the online lesson.

v. Tto explore the challengers faced by teachers in getting feedback from students. 


\section{Challenges Faced by Malaysian Government School Teachers to Conduct Online Lessons for the Secondary School Students during Covid-19 Pandemic}

\section{PROBLEM STATEMENT}

In the process of online education, teachers are facing challenges in delivering education through digital mediums especially during the beginning of the pandemic (Etxebarria.,et.al 2021). However, in Malaysian government schools, it can be identified that several challenges are faced by the secondary school teachers while conducting online studies. The challenges of the time consumption, the miscommunication challenges, interaction challenges, the challenge of engaging students involved in it and getting feedback from students. The challenges that are faced by the teachers in the process of delivering lessons digitally affect the education system and also the motivation of the students. Because of some difficulties, the teachers cannot provide their lessons properly; as a result, the students are also facing challenges in understanding the concepts of the lessons. Thus, this research is aimed to identify the problems faced by the teachers in government school in providing on line teaching effectively.

\section{Conceptual framework}

Dependant Variable

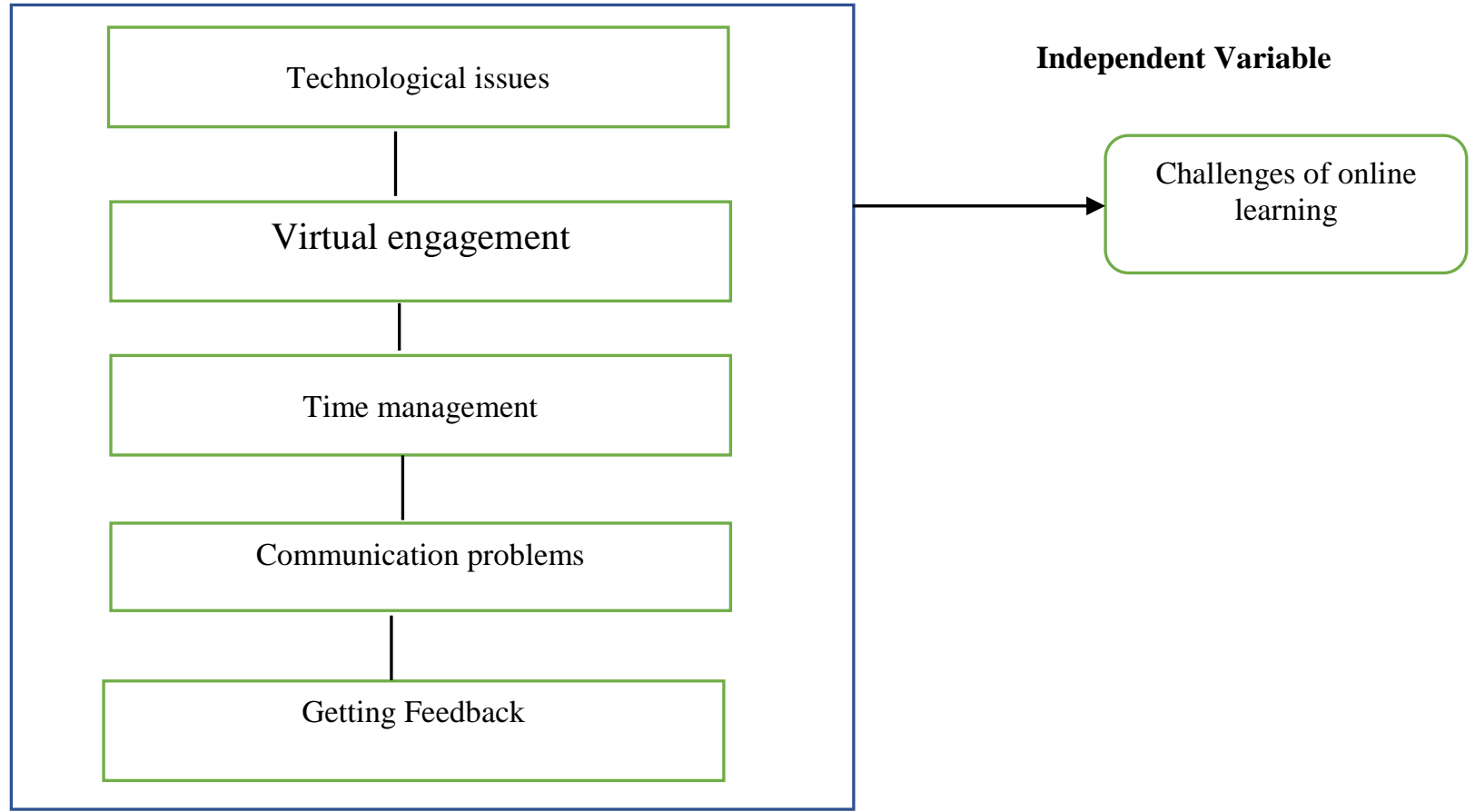

Diagram 1. Conceptual framework for challenges of online learning

\section{METHODOLOGY}

This qualitative research was conducted from March to May to June 2021. Researcher used a maximum variation sampling of 10 teachers from selected schools in Selangor. They were invited to participate in a telephone interview. In this research, the primary qualitative research methodology has been chosen. After the telephone interviews been conducted, the responses were recorded in google form by the samples. In the interviews, professional and personal semi structured questions have been asked to identify the challenges correctly. In the process of accessing the data from various primary resources, no monetary transactions have been involved.

\section{LITERATURE REVIEW}

The literature review will be discussed based on issues faced by teachers while conducting online lessons

\section{Technological issues}

Technological issues are one of the most common issues that teachers are face in conducting online classes. As per the views of Aliyyah.,et al. (2020), Some teachers may not have the gadgets to teach classes and some may face difficulties in handling the devices. This is due to their lack of technological skills. The online learning and teaching in Malaysia require improvement, especially in the quality of the interaction and instruction delivered during the course given to the students. Some improvements certainly should be implemented immediately to enhance the delivery of online teaching in Malaysia Selvanathan.,et al. (2020).

\section{Communication challenges}

Through the online classes, the teachers cannot interact appropriately with the students, as a result of the fact they face the challenge of miscommunication and cannot get the proper response from the students (Caena, 2021). Similar challenges have also been faced 


\section{Challenges Faced by Malaysian Government School Teachers to Conduct Online Lessons for the Secondary School Students during Covid-19 Pandemic}

in Malaysia. To overcome these difficulties, Yusuf (2013) suggests that institutions should provide more adequate e-learning platforms to increase and develop an interactive learning approach. Moreover, it is necessary to provide workshops or training for teachers and students to improve their technological and pedagogical competencies in online learning. Furthermore, during the current crisis, some countries have used different modalities for online learning to avoid the problems of the digital divide. New Zealand, for example, has a new approach. They using two television channels to provide educational content, joined with an Internet delivery and a hard-copy curriculum resource. With this method they able to over the syllabus for the children. (Mukhtar.,et.al, 2020).

\section{Time management}

According to Ahmad.,et.al (2019).The primary achievement of distance and regular students is managing time effectively. For some teachers, the new medium of teaching consumes more time to adopt the technologies, so they face the challenge of time consumption. Mismanagement of time can disturb the academic performance of learners and increase the stress level of the teachers (Rutil \& Gunasegaran).

\section{Virtual engagement}

For the virtual engagement with the students, the teachers cannot provide all notes online; they can only provide the study materials online. So, these processes can also lead to confusion among students about the concepts (ANU, 2021). Usually, students will recognise learning materials if they see them as valuable. Especially in remote classrooms, educators must recognize that students will only engage with course materials if seen as valuable. In online learning environments, it's important to help students engage with content in a way that makes sense for them. In Thailand most the educational staff are not prepared for online teaching activity. In this pandemic situation, in many educational institutions, the face-to-face teaching activity considered as a threat, so those teachers entirely focus on teaching in complimentary classes. The practical classes, seminars and part-time classes are not included in students' schedule . (Vanpetch., et.al, 2020).

\section{Getting feedback}

For online studies, the teachers are finding difficulties in getting feedback from the students. As a result, this will create confusion in finding a proper method of analysis (Romero \& Ventura, 2020). Unfortunately, in remote learning students, teachers have problems to get feedback from these passive learners.

\section{RESULTS AND ANALYSIS}

There are many strategies, and with the help of the process, the teachers can overcome the challenges of conducting online studies. Through the adaptation of technologies, it can increase the efficiency of their technical skills so that they can handle the gadgets properly. Training for computer literacy will help in mitigating the problem of technological issues. To engage more students in online classes, the teachers should produce PowerPoint presentations, short videos to encourage the students are essential (Boettcher \& Conrad, 2021). Conducting extra discussion classes in which the students can get the chance to solve their problems will help the students to remain more interested. Preparing proper assignments and conducting tests regularly will help in enhancing the skills and can help in attracting more students to online studies. By providing personal guidance to each of the students can help in getting proper feedback from the students that will help in improving the interaction also.

In Queensland (Australia), due to poor Internet connectivity television has been used to engage parents as well so that they can assist their children in learning. In Portugal, hard-copy teaching resources have been promptly delivered to children's homes thanks to a partnership between schools and post office services (Mukhtar., et al. 2020).

The teachers of Malaysian Government schools are facing challenges due to shifting their medium of studies from face to face to digital platform. Most teachers face challenges mainly because lack of technological knowledge and the less efficiency in using the technologies. (Darby \& Lang, 2019). The insufficient technological gadgets are also creating issues among teachers time management. (Nugroho. 2020). Not getting face-to-face interactions with the students can lead to miscommunication with the students. There are also some distractions among the students attending online classes from home, so the teachers are also facing challenges to garner attention from the students. So, after the analysis, the challenges can be identified, and overcoming the challenges for better improvement can also be recognized. From the responses of the respondents, it can be determined that the adaptation in technological advancements, proper training for the teachers, and good communication with the students help to solve the challenges. Technical training is also needed for enhancing the technical skills of the teachers. As a result of the activity, it will help them to handle the technologies more comfortably. They can also express their concepts firmly. The implementation of some doubt clearing classes for the students will help the teachers to evaluate each of the students personally and help them to reduce the confusion about the concept of the studies. 


\section{Challenges Faced by Malaysian Government School Teachers to Conduct Online Lessons for the Secondary School Students during Covid-19 Pandemic}

The importance of improving the computer literacy of the teachers to mitigate the challenges of delivering lessons digitally. Online learning requires teachers to have a basic understanding of using digital forms of learning. Teachers have a very basic understanding of technology. (Gautam, 2020). Computer literacy is essential to understand these days as during covid-19 schools were being closed, and online training was introduced. Most of the teachers only know the basic operations of computers. In fact, understanding the DELIMA platform is a challenge for some senior teachers. The inefficiency in teaching practices will happen if they are not technologically sound. There will be a big communication gap between the teachers and students as they will not convey the information correctly. Being technologically advanced will help them to create unique ways of teaching, giving students an audio-visual impact that was not present in a classroom.

As stated by Ratheeswari (2018), it has been proven that being technologically advanced will help the students, and also there is a requirement for teachers to be technologically advanced. It is also confirmed that it will bring confidence among them to deliver a lesson properly. Being technologically advanced, the teachers can quickly learn the online mediums like being able to access and use an online medium or being able to make a pre-recorded video for the students to see later which will be very helpful. Even being able to record the sessions taught by the teachers will be beneficial in the long run as the students can listen to the recording whenever they want. This is a unique blessing that was not available before. Thus, it is proved that being able to be technologically sound will therefore help to mitigate the challenges.

The importance of implementing web technologies to overcome the challenges of the teachers in online studies

The knowledge about different technologies will to help give valuable insights that are required, and they might also get to know other things through the software, which would be great. It has been proved that due to covid-19, there is a communication gap created between the teachers and students, which can be closed by using the software or other technological mediums. It has also been proven that the knowledge for learning these technologies for example Google Apps, DELIMA platform by Ministry of Education, Zoom and ext. must be given tutorials or documents, which will tell them the step-to-step description of knowing the process of installing the software or accessing a particular website. The details should be given such as which browser to access after what or where and how to store the software in the computer. Below is the finding of the interview:

\section{INTERVIEW RESPONSES}

1) What are the challenges faced by you while providing online tutorials?

\begin{tabular}{|l|l|}
\hline Teacher 1,4,6,10 & $\begin{array}{l}\text { The process of online studies faces time consumption, } \\
\text { miscommunication challenges in many ways. }\end{array}$ \\
\hline Teacher 2,7,8,5,9 & $\begin{array}{l}\text { The process of online studies faces the challenges of poor } \\
\text { application of technologies. }\end{array}$ \\
\hline Teacher 3 & $\begin{array}{l}\text { I don't think the process is facing challenges. It will give enough } \\
\text { opportunities to maintain the flow of studies. }\end{array}$ \\
\hline
\end{tabular}

Table 1: Responses of the teachers about the challenges that are faced while conducting online studies

2) What do you think about the activities that can be taken to mitigate the challenges?

\begin{tabular}{|l|l|}
\hline Teacher 1,2,6 & $\begin{array}{l}\text { Through the implementation of a better communication medium } \\
\text { will help in mitigating the challenges. }\end{array}$ \\
\hline Teacher 4,5,7,10,9 & Through many doubts clearing sessions, it can be possible. \\
\hline Teacher 3,8 & No, I don't think so. I think that the procedures are enough. \\
\hline
\end{tabular}

Table 2: Responses of the teachers regarding the process of overcoming the challenges

3) Do you think that technological training platform regarding online classes is necessary to meet the challenges?

\begin{tabular}{|l|l|}
\hline Teacher 1,4,10,9 & $\begin{array}{l}\text { Yes, I think that proper training is needed for better teaching } \\
\text { method. Especially various online platforms. The training session } \\
\text { (LADAP) in school is not sufficient. }\end{array}$ \\
\hline Teacher 3 & $\begin{array}{l}\text { No, I think it is not necessary to provide training for the teachers } \\
\text { during this pandemic. }\end{array}$ \\
\hline Teacher 2,7,8,5 & $\begin{array}{l}\text { Yes, I think that the training is needed. By the implementation of } \\
\text { proper training in DELIMA it will help in increasing efficiency to } \\
\text { handle technologies. }\end{array}$ \\
\hline
\end{tabular}

Table 3: Responses of the teachers regarding the necessity of providing training. 
Challenges Faced by Malaysian Government School Teachers to Conduct Online Lessons for the Secondary School Students during Covid-19 Pandemic

4) Do you think that the improvement of technological infrastructure is necessary to get outcome from students during online learning?

\begin{tabular}{|l|l|}
\hline Teacher 1,5,6,10 & $\begin{array}{l}\text { Yes, I think that technologies should be implemented to overcome outcome } \\
\text { issues. }\end{array}$ \\
\hline Teacher $\mathbf{2 , 4 , 7 , 9}$ & Yes, I think that with technological advancements the process will be better. \\
\hline Teacher 3,8 & $\begin{array}{l}\text { No, I think that the technologies will not mitigate the challenges of the } \\
\text { teachers }\end{array}$ \\
\hline
\end{tabular}

Table 4: Responses of the teachers regarding the improvement of technologies

5) What is your opinion about the challenges in delivering lessons digitally affecting the communication with students?

\begin{tabular}{|l|l|}
\hline Teacher $\mathbf{1 , 5 , 6}$ & Yes, I think that the challenges affect the study of the students. \\
\hline Teacher $\mathbf{2 , 4 , 7 , 1 0}$ & $\begin{array}{l}\text { Yes, I think that it can slow the progress of the communication system. } \\
\text { Because of the challenges we cannot deliver the lessons to the students } \\
\text { properly. }\end{array}$ \\
\hline Teacher 3,8,9 & I think that the challenges don't cause any harm to communication \\
\hline
\end{tabular}

Table 5: Responses of the teachers regarding the effect of the challenges on the study of the students.

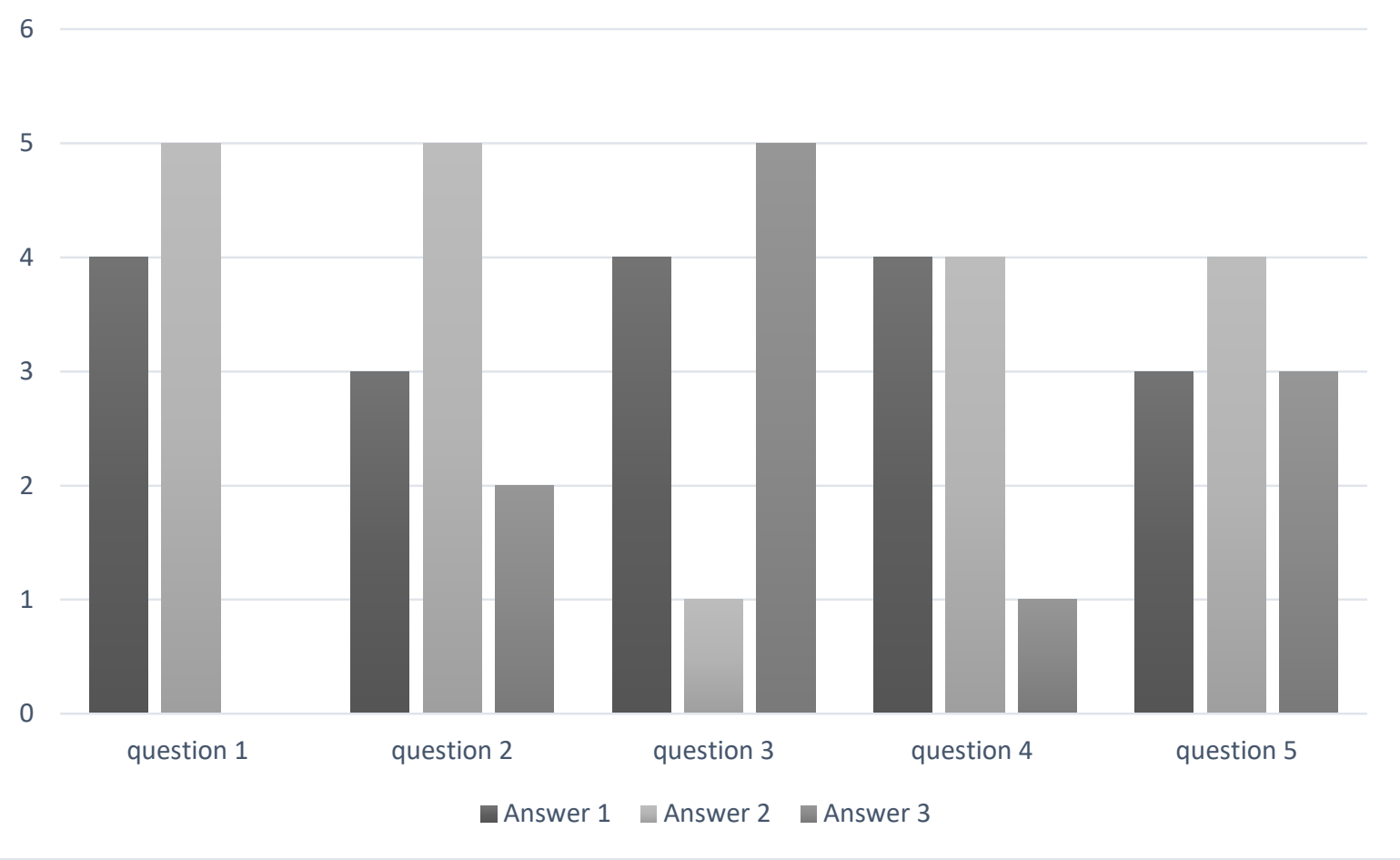

Diagram 2: Responses from Teachers regarding challengers of online teaching

\section{CONCLUSION}

It can be concluded that the teachers' challenges for adopting the digital technological systems also affect the educational system and communication process with students. The justifications for the research are considered to meet the objectives of the investigation. By the implementation of some well-organized strategies and technologies in the digital system, it will help in reducing the challenges for the teachers to conduct online classes. Furthermore, the poor application of technologies by teacher, can demotivate students and reduce feedback from students. Teachers really need proper training and coaching to learn about digital platforms and improve teacher-student communication process. Thus, in every crisis, there is always an opportunity. Perhaps, in this case, it is an opportunity for teachers and institutions to focus on the technological platforms' quality improvement trainings for teachers. According to Yingsak \& Vanpetch 2020, we should learn from mistakes and scale-up digitization, hybridization and ubiquitous learning. Online courses are not as effective as face-to-face classes, but they are better than no classes at all, (Leob, 2020). This is the valuable experience for institutes, government and teachers to always up to date with technological knowledge to face future challenges. 
Challenges Faced by Malaysian Government School Teachers to Conduct Online Lessons for the Secondary School Students during Covid-19 Pandemic

REFERENCE

1) Ahmad, S. Batool, A., \& Choudhry, A.H. (2019). Path relationship of time management and academic achievement of students in distance learning institutions. Pakistan Journal of Distance and Online Learning, 5(2), 191-208. https://files.eric.ed.gov/fulltext/EJ1266710.pdf

2) Aliyyah, R. R., Rachmadtullah, R., Samsudin, A., Syaodih, E., Nurtanto, M., \& Tambunan, A. R. S. (2020). The perceptions of primary school teachers of online learning during the COVID-19 pandemic period: A case study in Indonesia. Journal of Ethnic and Cultural Studies, 7(2), 90-109. http://dx.doi.org/10.29333/ejects/388

3) ANU V (2021), Online Learning Challenges \& How to Overcome These Problems General Education [ONLINE],https://www.embibe.com/exams/online-learning-challenges-and-solutions/

4) Boettcher, J. V., \& Conrad, R. M. (2021). The online teaching survival guide: Simple and practical pedagogical tips. John Wiley \& Sons. New Jersey, United States.

5) Boon for online learning for kids. (May 28,2020). Momspresso. https://www.momspresso.com/parenting/8fffb8358fa240e0abf113005e80b918/article/boon-of-learning-for-kids-wuz1j4

6) Caena,F (2021), Aligning teacher competence frameworks to 21st-century challenges WILEY [ONLINE], https://onlinelibrary.wiley.com/doi/pdfdirect/10.1111/ejed.12345

7) Darby, F., \& Lang, J. M. (2019). Small teaching online: Applying learning science in online classes. John Wiley \& Sons. New Jersey, United States.

8) Etxebarria, O.N.,Santxo,B.N.,Mondragon,I.N \& Santamaria. D.M, (12 January 2021 ) The psychological State of Teachers During the Covid-19 Crisis: The Challenges of Returning to Face -to-face Teaching. Frontiers in psychology. https://doi.org/10.3389/fpsyg.2020.620718

9) Gautam, P (October 10,2020). Advantages And Disadvantages Of Online Learning. E learning Industry. https://elearningindustry.com/advantages-and-disadvantages-online-learning

10) Hazlin Hassan, (APR 22, 2021). Spread of Covid-19 in Malaysia schools sparks calls for return to virtual learning. The new straits time. https://www.straitstimes.com/asia/se-asia/spread-of-covid-19-in-malaysia-schools-sparks-calls-forreturn-to-virtual-learning

11) Leob, S (March 20, 2020). How Effective Is Online Learning? What the Research Does and Doesn't Tell Us. Educational week. https://www.edweek.org/by/susanna-loeb

12) Nugroho, A (2020), Teaching Activities and Challenges during COVID-19 Pandemic ACADEMIA [ONLINE], https://d1wqtxts1xzle7.cloudfront.net/63464185/EFL_Classes_Must_Go_Online_Teaching_Activities_and_Challenges during Covid-19 Pandemic

13) Mukhtar, K., Javed, K., Arooj, M., \& Sethi, A. (2020). Advantages, Limitations and Recommendations for online learning during COVID-19 pandemic era. Pakistan Journal of Medical Sciences, 36(COVID19-S4). https://doi.org/10.12669/pjms.36.COVID19-S4.2785

14) Romero, C., \& Ventura, S. (2020). Educational data mining and learning analytics: An updated survey. Wiley Interdisciplinary Reviews: Data Mining and Knowledge Discovery, 10(3), e1355. New Jersey, United States.

15) Rutil Taising \& Gunasegaran Karuppannan, (2020). Principals' Management Empowerment Practices And Its Relationship With Work Satisfaction Among School Mid-Level Administrators. Selangor Humaniora Review. Malaysia. Vol 4 (2) December 2020. http://share.journals.unisel.edu.my/ojs/index.php/share/article/view/117

16) Selvanathan,M.,Nur Atikah, M.H., Nur Alyani, N.A (2020). Students learning experiences during COVID-19: Work from home period in Malaysian Higher Learning Institutions. Sage publications. https://doi.org/10.1177\%2F0144739420977900.

17) Vanpetch, Y \& Sattayathamrongthian, M (2020). The challenge and opportunities of thailand education due to the covid19 pandemic: case study of Nakhon Pathom, 